Research Article

\title{
Plasma-Treated CVD Graphene Gas Sensor Performance in Environmental Condition: The Role of Defects on Sensitivity
}

\author{
Gil Capote Mastrapa $\mathbb{D D}^{1}$ and Fernando Lazaro Freire $\mathrm{Jr}^{2}$ \\ ${ }^{1}$ Brazilian Center for Research in Physics, Rio de Janeiro, Brazil \\ ${ }^{2}$ Pontifical Catholic University of Rio de Janeiro, Rio de Janeiro, Brazil \\ Correspondence should be addressed to Gil Capote Mastrapa; gcapote@cbpf.br
}

Received 17 June 2019; Revised 23 August 2019; Accepted 9 September 2019; Published 4 November 2019

Academic Editor: Sang Sub Kim

Copyright ( 2019 Gil Capote Mastrapa and Fernando Lazaro Freire Jr. This is an open access article distributed under the Creative Commons Attribution License, which permits unrestricted use, distribution, and reproduction in any medium, provided the original work is properly cited.

\begin{abstract}
In this work, a low-cost resistive gas sensor based on graphene grown by CVD was fabricated and its sensitivity was studied in terms of defect density. CVD graphene was transferred using Polyurethane as sacrifice layer with low contamination and defect-free results. An atmospheric plasma etching system was used to homogeneously induce defects on the sensor's active area, as investigated through Raman spectroscopy. Device sensing properties were significantly enhanced for greater defect density for both $\mathrm{NH}_{3}$ and $\mathrm{NO}_{2}$. The modified sensors were submitted to different concentrations of both target gas to assess detection limits and overall behavior. It was revealed that defective CVD graphene devices possess sensitivity up to ppm range with linear dependence in the range of values measured. The fabricated sensors presented little to no signal degradation after months of atmospheric exposure.
\end{abstract}

\section{Introduction}

Since graphene first gas detection investigation published in 2007 [1], numerous efforts have been made towards its extended application in the area $[2,3] .2 \mathrm{D}$ materials, such as graphite, have attracted enormous attention given that they usually show different properties from their threedimensional counterparts. Since most chemical sensors are based in the interaction between an active surface and a target gas, it is straightforward to understand that graphene's extremely high surface area/volume ratio makes it ideal for its use in gas sensing devices.

In this regard, the need to growth and isolate largearea graphene on suitable substrates for electronic applications becomes apparent. Chemical Vapor Deposition has been used for many years as a suitable option for the growth of polycrystalline graphene, with a highly reproducible process and sufficient quality for most requirements $[4,5]$. CVD-grown graphene natural defects are also somewhat desired, as defects and irregularities are well-known adsorption sites in most solid state gas sensors in use today $[6,7]$.

On the other hand, too many defects in the graphene surface may promote adsorption but also have a substantial effect in the film electrical conductivity. A typical example of this is seen in graphene oxide films: as deposited, they present an enormous amount of adsorption sites given by its sheet irregular agglomeration, which conversely causes high resistance values and poor effective contact [8].

Numerous $a b$ initio studies have found that defects on graphene enhance its sensing properties (DFTs) and experimental works have confirmed this behavior [9-11]. It has been shown in the work by Salehi-Khojin et al. [9] that defective graphene is not only more sensitive than pristine but also that a combination of different types of defects is desired. Lastly, it has also been reported by Rigoni et al. [12] that UV radiation may increase the sensor's response by introducing defects and aiding desorption during the recovery process. Despite all that, the mechanism of response of the graphene properties to the variation of defect density for 


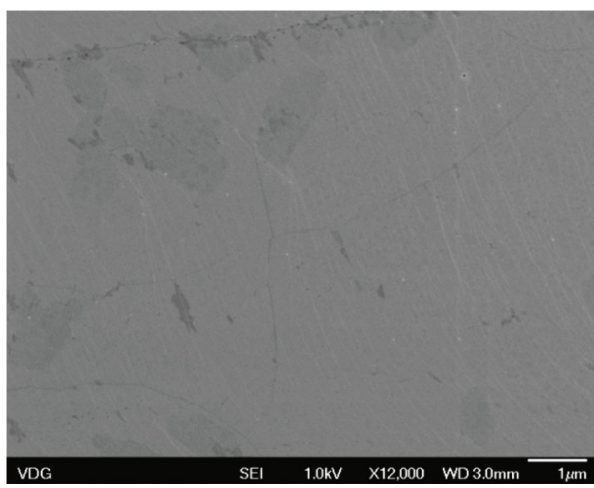

(a)

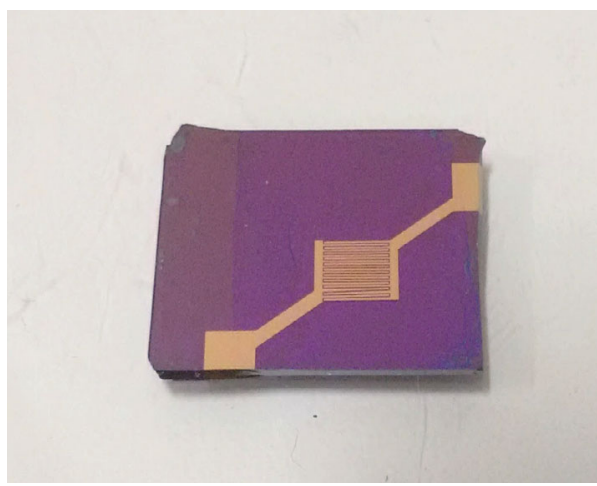

(c)
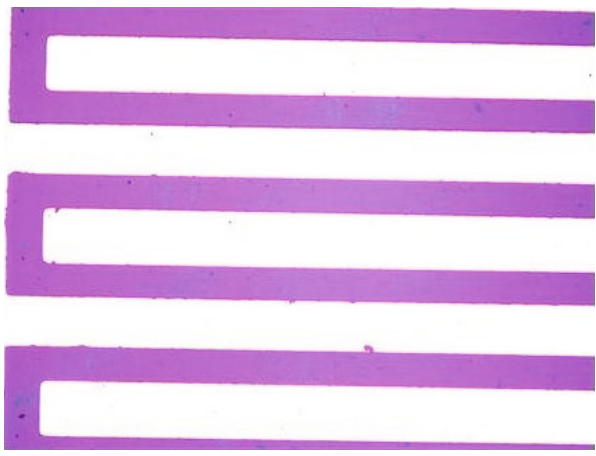

(e)

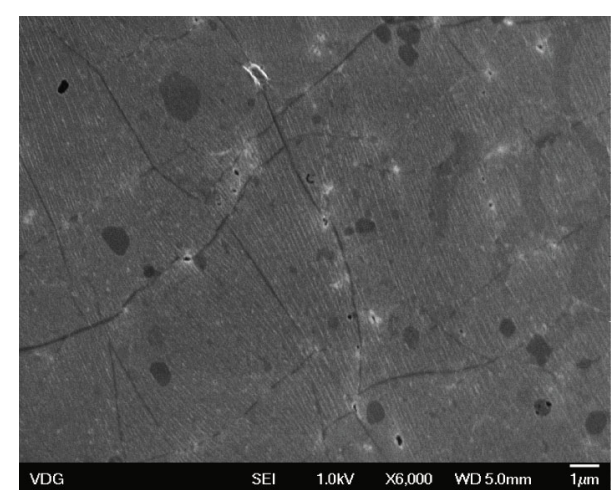

(b)

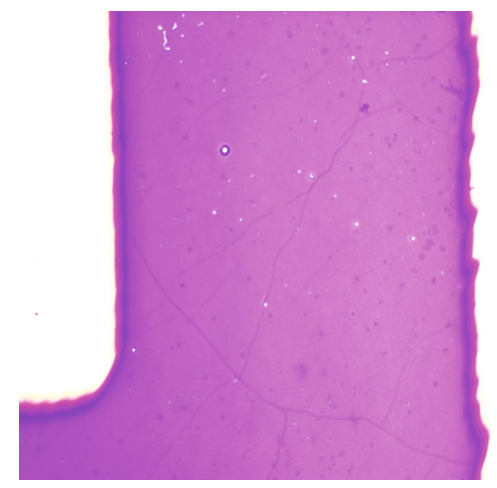

(d)

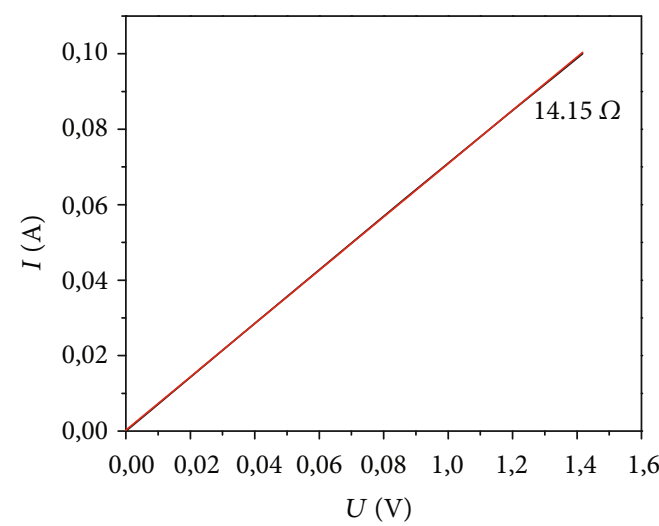

(f)

Figure 1: SEM images of CVD graphene as grown on $\mathrm{Cu}$ (a) and after transferred onto $\mathrm{SiO}_{2} / \mathrm{Si}$ (b). (c-e) Details of the interdigitated chemiresistor; (d) I/V graphic. Distance between fingers is 60 microns.

CVD graphene in an atmospheric environment is yet to be fully understood.

In this work, we studied graphene sensing properties upon successive increases in uniformly distributed defects. To obtain this homogeneously defect density, atmospheric plasma etching was used. $\mathrm{NO}_{2}$ and $\mathrm{NH}_{3}$ were chosen as target gases. The two analytes studied in this work are among the most treated for research in the field, because these toxic gases have been demonstrated to have significant negative impacts on health and the environment. However, the dangerousness towards analytes mostly depends on some parameters related to the exposure time. To this aim, different definitions of limit values and accordingly thresholds can be considered, taking into account different endpoints or averaging times. Independently from the various definitions and the countries taken into account, the analyte concentration ranges to not exceed are quite stringent. Indeed, the general aim of research and technology is to find routes to make possible the detection and measurement of gases at levels of ppm.

Raman spectroscopy was used to monitor defect density and distribution [13]. It was shown that defective sensors presented enhanced response to the same concentration of both target gases. A higher sensitivity was observed for $\mathrm{NO}_{2}$, which may be explained by the water adsorption on the sensor surface as seen in [12]. It was also revealed that 


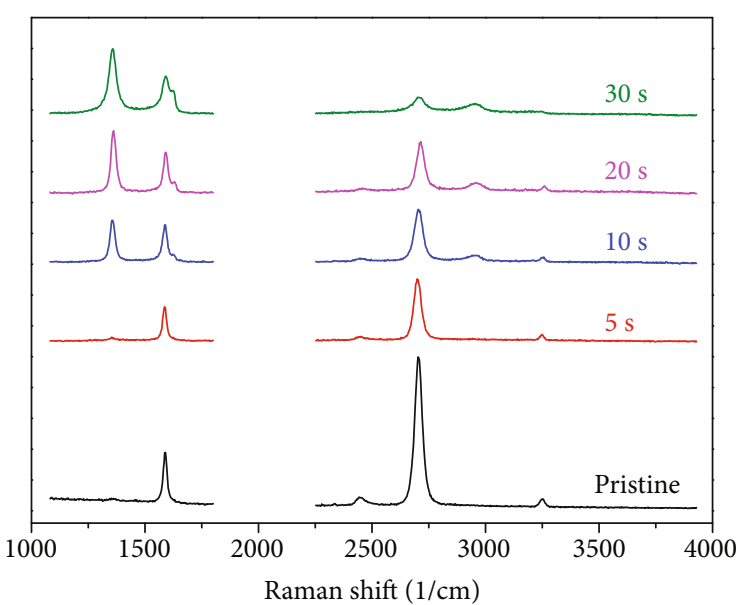

(a)

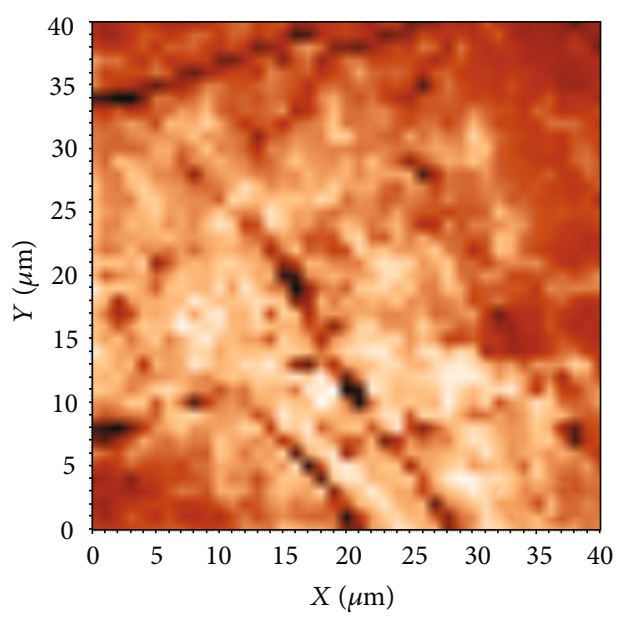

(c)

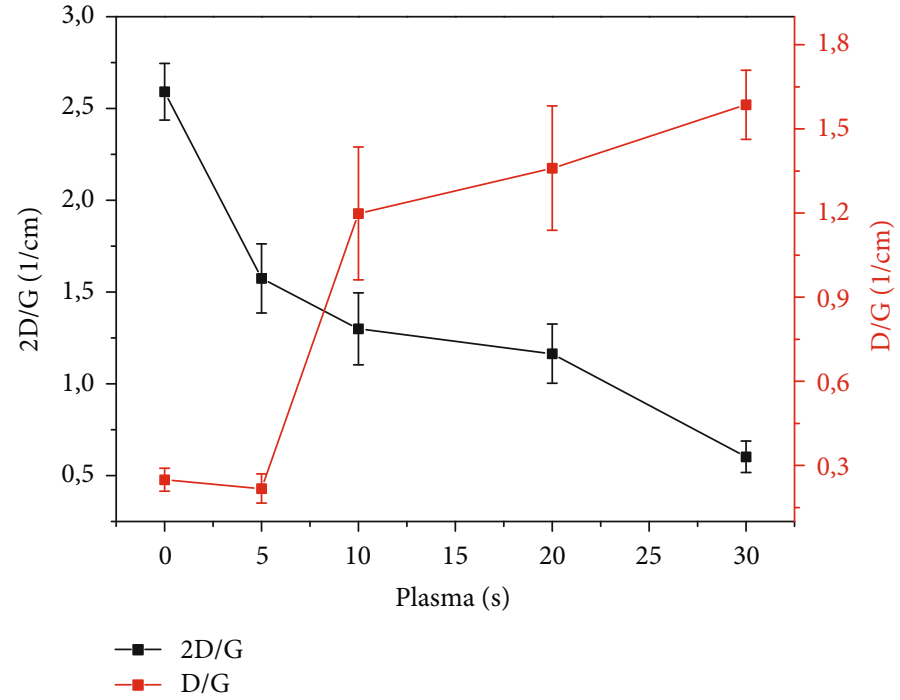

(b)
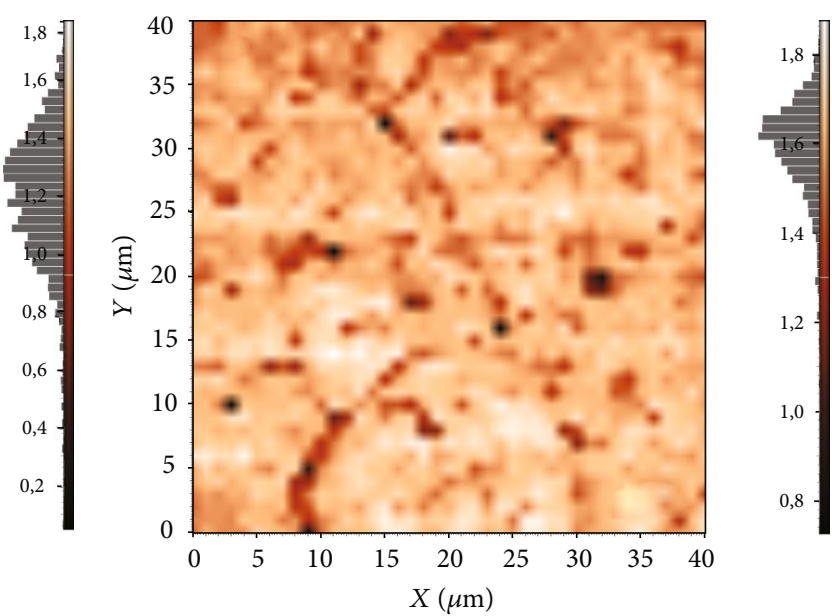

(d)

Figure 2: Raman spectra of typical samples before and after plasma treatment (a), (b) $\left(I_{2 \mathrm{D}} / I_{\mathrm{G}}\right)$ and $\left(I_{\mathrm{D}} / I_{\mathrm{G}}\right)$ ratios for the sample series; (c-d) Raman maps for 10 seconds and 30 seconds of plasma exposure, respectively.

the as-fabricated defective sensors present linear response variation with concentration for both gases, with detection limits ranging to the few ppm scale.

\section{Experimental Details}

All sensors used monolayer graphene grown on copper foils by Low Pressure Chemical Vapor Deposition (LPCVD), using a $\mathrm{H}_{2}$ annealing flux and methane gas as precursor at $1050^{\circ} \mathrm{C}$ and $500 \mathrm{mTorr}$ of total pressure. All films were transferred on to $\mathrm{SiO}_{2} / \mathrm{Si}$ substrates using a modified wet-transfer method using Polyurethane (PU) as sacrifice layer and Tetrahydrofuran (THF) as solvent. PU thin films were spincoated on the graphene surface, and the copper was subsequently etched using an iron chloride $\left(\mathrm{FeCl}_{3}\right)$ solution for 1 hour. After transferring graphene on to the silicon dioxide substrate, PU film was removed by rinsing in THF for 3 hours. Scanning electron microscopy (SEM) images were obtained using a FEG-SEM model JSM-6701F from JEOL. SEM images of the as-grown graphene sheets on copper and after the transfer process onto $\mathrm{SiO}_{2} / \mathrm{Si}$ as described are shown in Figures 1(a) and 1(b), respectively.

After transferred, chemiresistors were fabricated by thermal evaporation of $\mathrm{Cr} / \mathrm{Au}(5 / 45 \mathrm{~nm})$ contacts on top of the graphene films on $\mathrm{SiO}_{2} / \mathrm{Si}$ using a mask as shown in Figures $1(\mathrm{c})-1(\mathrm{e})$. The distance of the graphene active area between the interdigitated electrodes was 60 microns. Ohmicity was checked through I-V curves measured using a Keithley 2400 SourceMeter connected to a sample mounting board, model Ecopia SPCB-1. The corresponding I/V graph is shown in Figure 1(f).

Defects were introduced by atmospheric plasma etching through a Harrick plasma model PDC-32G. The amount of defects was adjusted depending on period of exposure, going from $5,10,20$, and up to 30 seconds. Each sample was then submitted to Raman spectroscopy to quantify defect density, 


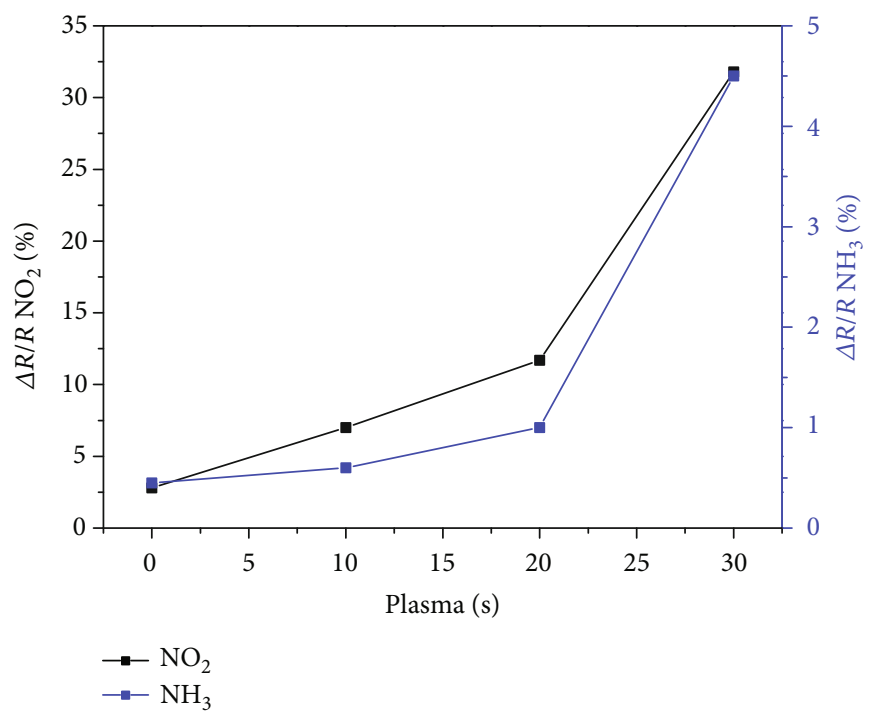

Figure 3: Sensor response to $\mathrm{NO}_{2}$ and $\mathrm{NH}_{3}$ as a function of the time of plasma treatment.

using a NTEGRA spectrometer from NT-MDT with emission wavelength of $473 \mathrm{~nm}$.

Each sample was then mounted onto the sample holder and placed inside a cylindrical stainless steel chamber (1.7 litters of volume) with a small diaphragm pump installed for vacuum. Commercial traceable standard mixtures supplied by Linde Industrial Gases of $100 \mathrm{ppm}$ of $\mathrm{NH}_{3}$ and $150 \mathrm{ppm}$ of $\mathrm{NO}_{2}$, both on a nitrogen base, were used to test the sensor's performance. All measures were made at room temperature $(295 \mathrm{~K})$ and $50 \%$ relative humidity, and total pressure inside the chamber was adjusted to 700 torr. MKS Instruments mass flow controllers were used for gas release $\left(\mathrm{NH}_{3}\right.$ and $\mathrm{NO}_{2}$ mixtures, $99.99 \%$ pure $\mathrm{N}_{2}$ also from Linde or air).

Initially, the samples were placed in vacuum for a period of 3 hours in which a resistance baseline value was attained, with less than a $0.5 \%$ variation observed in 10 minutes. Then, an air flux was released and the baseline readjusts to the new conditions in approximately one hour. After that, the air flux was substituted by a controlled moisture flux, keeping pressure constant throughout the measurement. Typical exposure time to both target gases was set to 10 minutes. Finally, an air flow was used for device recovery.

The fabricated devices presented little to no signal degradation after 3 months of atmospheric exposure.

\section{Results and Discussion}

As previously discussed, defects were generated by atmospheric plasma as appreciated by Raman spectroscopy shown in Figure 2(a). The $2 \mathrm{D}$ band $\left(\sim 2700 \mathrm{~cm}^{-1}\right)$ and $\mathrm{G}$ band $\left(\sim 1580 \mathrm{~cm}^{-1}\right)$ intensity ratio $\left(I_{2 \mathrm{D}} / I_{\mathrm{G}}\right)$, a well-known indicator of monolayer graphene, decreases with higher plasma exposure times as expected, while the $\mathrm{D}$ band $\left(\sim 1360 \mathrm{~cm}^{-1}\right)$ vs. $\mathrm{G}$ band intensity ratio $\left(I_{\mathrm{D}} / I_{\mathrm{G}}\right)$ rises, as shown in Figure 2(b). This latter indicator usually is mainly associated with the presence of defects. It has been also established that high $D$ peak intensity in conjunction with the appearance of a
$\mathrm{D}^{\prime}$ band $\left(\sim 1620 \mathrm{~cm}^{-1}\right)$, as observed, further signals defects in the graphene structure [13].

Even more, it has been reported that the value of intensity ratio between the $\mathrm{D}$ and the $\mathrm{D}^{\prime}$ bands $\left(I_{\mathrm{D}} / I_{\mathrm{D}^{\prime}}\right)$ indicates the prevalence of different types of defects in a graphene sample, $(\sim 13)$ for $s p^{3}$ defects and ( 7) for vacancy-like defects [14]. In this regard, it may be inferred from the measurements that initial bombardment created numerous $s p^{3}$-related defects, but eventually the $\mathrm{D}^{\prime}$ band higher intensities for higher exposure periods denotes vacancy-dominated samples.

Raman maps showed that plasma-created defects were homogeneously distributed, as shown through Raman maps for 10 seconds (Figure 2(c)) and 30 seconds (Figure 2(d)) of plasma exposure. Local Raman spectrum variation, observed mainly in the form of cracks and wrinkles in the film, was all due to growth and transfer-related processes. Image histograms of $\left(I_{\mathrm{D}} / I_{\mathrm{G}}\right)$ ratio indicates the presence of highly uniform surfaces, more so for higher exposure periods.

The values corresponding to $\mathrm{G}$ and $2 \mathrm{D}$ bands presented a slight blue shift as the exposure time increased, caused mainly because of the broadening of the peaks caused by the induced defects. Both Raman maps presented in Figure 2 average shift values (in the whole map) for the $\mathrm{G}$ and $2 \mathrm{D}$ peaks were $1589.4 \mathrm{~cm}^{-1}$ and $2709.1 \mathrm{~cm}^{-1}$ for the 10-second plasma exposure and $1592.5 \mathrm{~cm}^{-1}$ and $2711.4 \mathrm{~cm}^{-1}$ for the 30 -second exposure. Both $\mathrm{G}$ and $2 \mathrm{D}$ shifts are an indicator of the p-type behavior the sensors showed.

In Figure 3, we resume response of the sensor to exposition to different gases as a function of the time of plasma treatment. It is clear that the response increases upon the increase of the duration of the processing. The response of the sensor is illustrated also in Figures 4(a) and 4(b). The response changes as a function of plasma exposure as seen in Figures 4(a) and 4(b). In Figures 4(c) and 4(d), it was shown for plasma processing time of 30 minutes the recovery behavior of the sensor. Total recovery was not achieved, signaling that full desorption might require further treatment. 


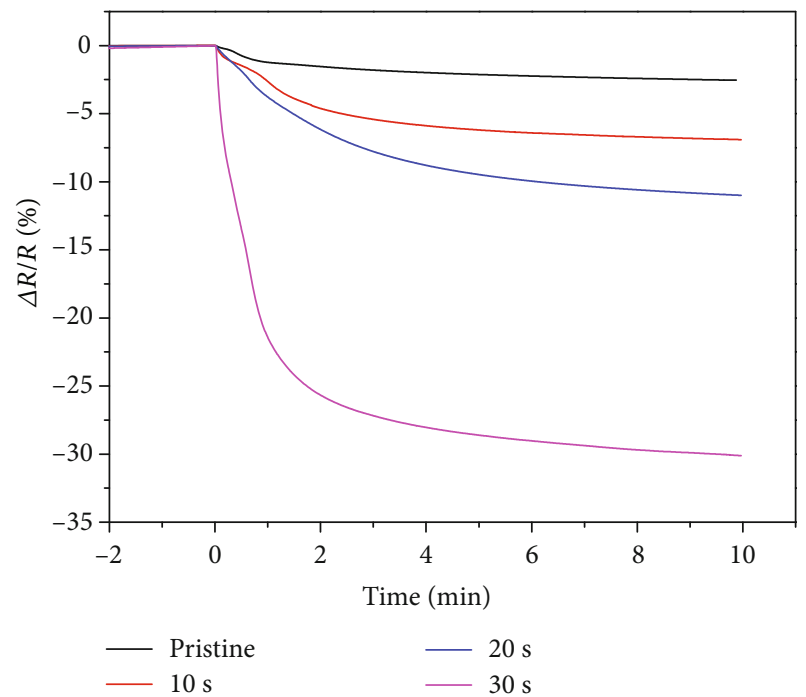

(a)

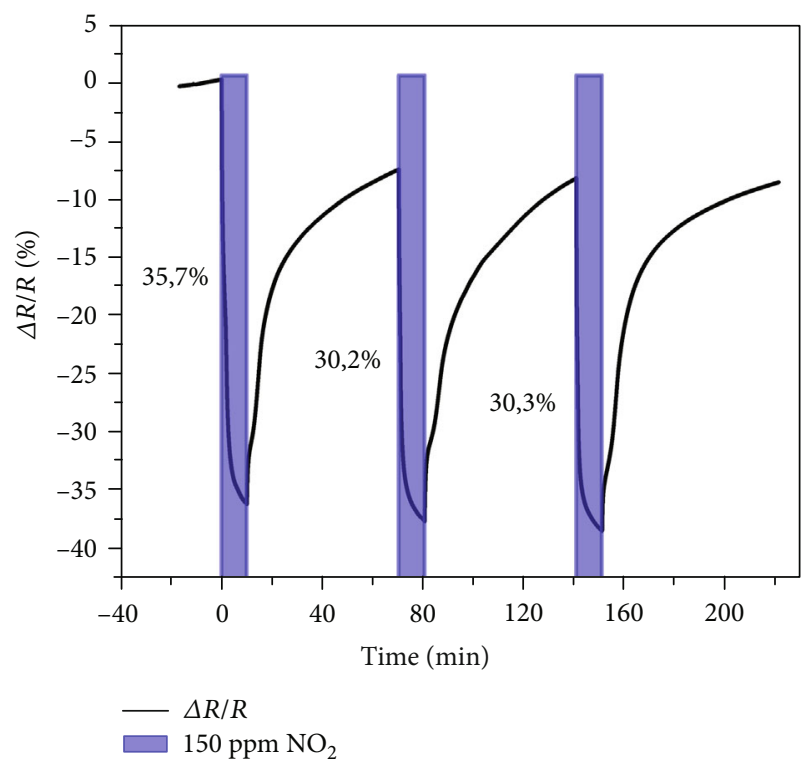

(c)

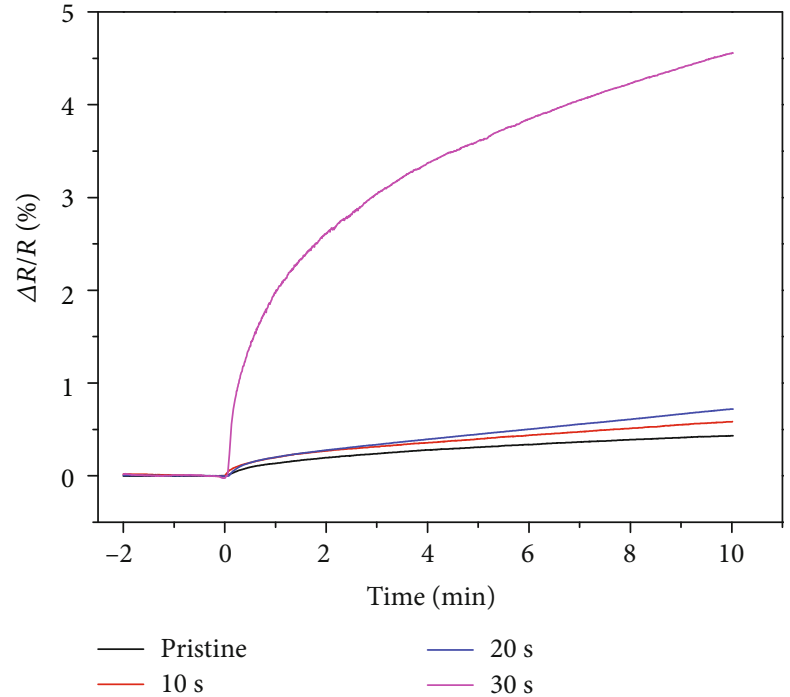

(b)

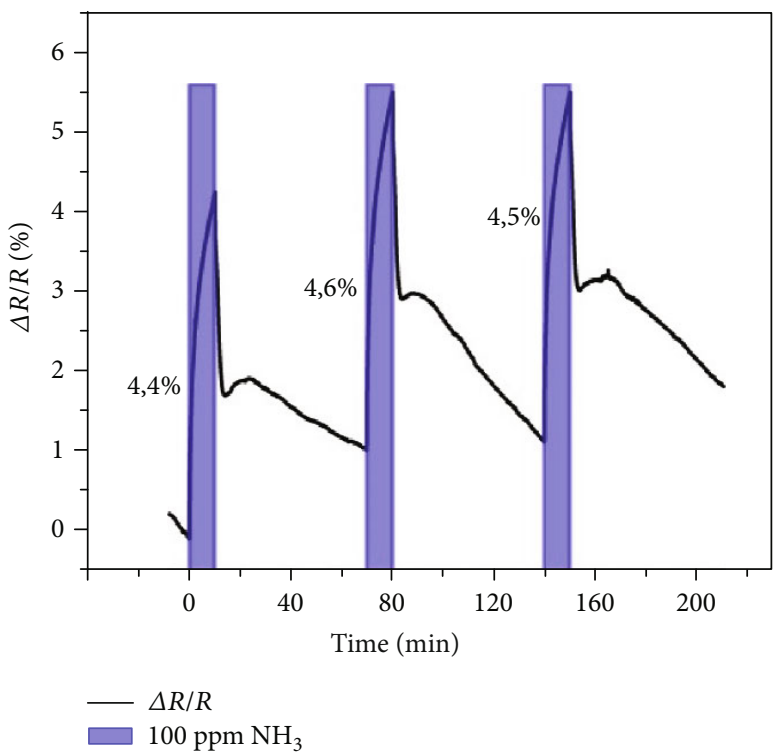

(d)

FIGURE 4: CVD graphene sensor response to $150 \mathrm{ppm}$ of $\mathrm{NO}_{2}$ (a) and $100 \mathrm{ppm}$ of $\mathrm{NH}_{3}$ (b) for as-transferred and plasma-treated samples. (c-d) Sequential exposure to both gases for a 30-second-exposed sample.

However, it was not identified a clear relation between recovery rates and plasma exposure time.

It was also investigated the sensor performance when submitted to different concentrations of the target gases. For this, an additional pure nitrogen flux was introduced to the previous target gas mixtures in-flux, in such way that the total flux released into the chamber remained constant. When exposed to different concentrations of $\mathrm{NH}_{3}$ and $\mathrm{NO}_{2}$ , as shown in Figures 5(a) and 5(b), the sensors registered clear signals up into the range of tens of ppm. It was also found that the response is directly proportional to the concentration of the target gas as shown in Figure 5(c). From the linear regression curves of both series, it may be estimated that below $2 \mathrm{ppm}$ for $\mathrm{NH}_{3}$ and $18 \mathrm{ppm}$ of $\mathrm{NO}_{2}$ the response will no longer be reliable.

\section{Summary and Conclusions}

In summary, monolayer CVD-grown graphene sheets were transferred to $\mathrm{SiO} 2 / \mathrm{Si}$ substrates using $\mathrm{PU}$ as sacrifice layer in the transfer process. A chemiresistor was fabricated on top of the as-transferred graphene layer, and homogeneous defects were then induced by plasma. The density and type of defects produced were investigated as a vital factor in the sensor response. Raman spectroscopy proved uniformly distributed defects in the graphene sheet after plasma exposure. Device sensing properties were highly influenced by the defect density for both $\mathrm{NO}_{2}$ and $\mathrm{NH}_{3}$ gases. In general, all devices showed greater response to $\mathrm{NO}_{2}$, which may be explained by the predominant number of vacancytype defects caused by plasma etching. All devices showed 


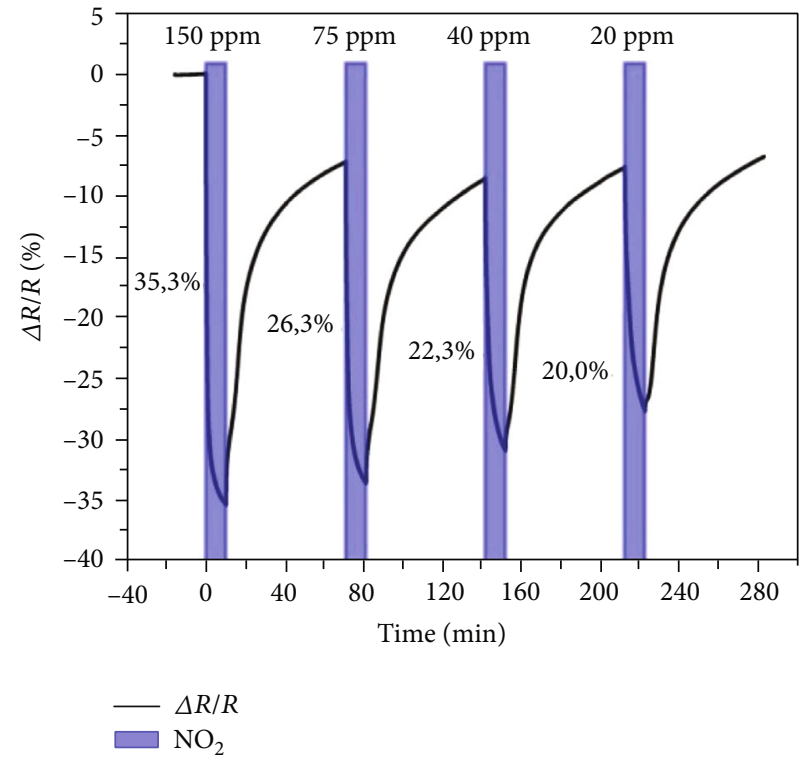

(a)

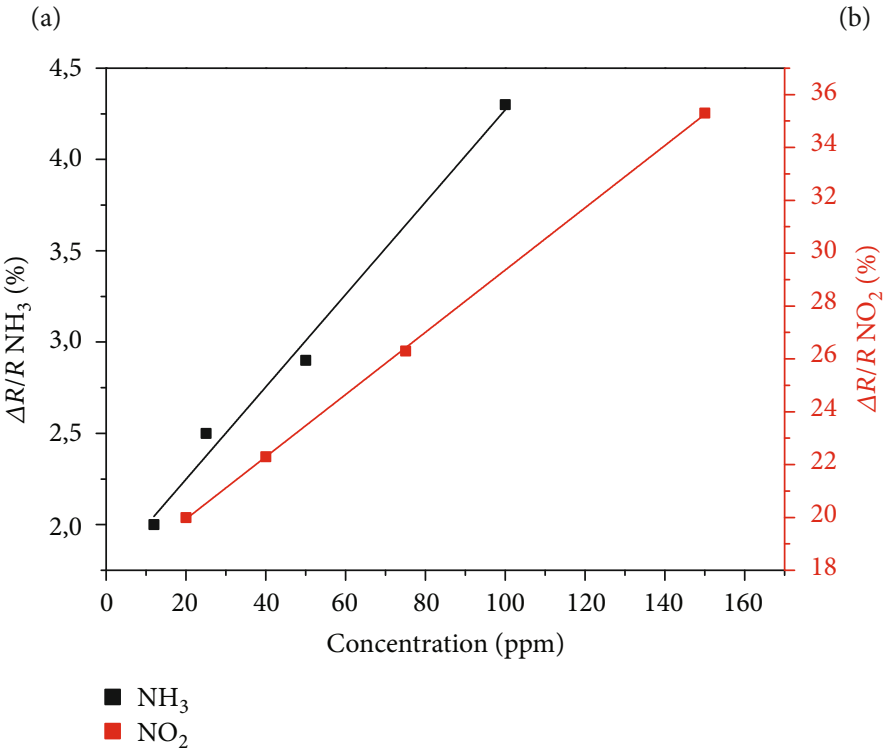

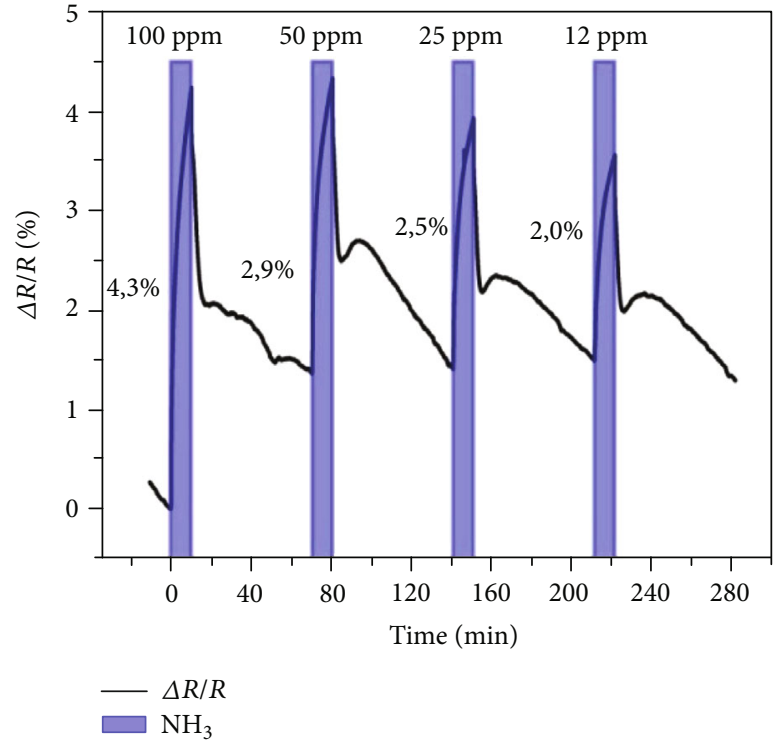

(b)

(c)

FiguRE 5: Real-time behavior of a 30-second plasma-treated device upon exposure to sequential $\mathrm{NO}_{2}$ (a) and $\mathrm{NH}_{3}$ (b) pulses at decreasing concentrations. (c) Registered response for each gas.

almost complete desorption when exposed to air and a response was recorded up to tens of ppm range for both gases. The as-created chemiresistors showed low resistance and an enhanced response to both target gases, all of that while not showing any signal degradation after atmospheric exposure.

To be competitive with commercial sensor technologies, graphene-based sensors must be mass producible at low cost. With the recent improvement of the CVD synthesis method [5], the issue of large-scale graphene production is apparently about to be overcome. In our devices, another bottleneck which is the need of high-temperature desorption for gases of $\mathrm{NO}_{2}$ and $\mathrm{NH}_{3}$ on graphene surfaces is surmount, as is clear from Figures 4 and 5. Concluding, the increase in sensor sensitivity is the result of simple plasma treatment using air as the active gas, clearly indicating that this device is on the route to be commercially competitive.

\section{Data Availability}

All the data used to support the findings of this study are available from the corresponding author upon request.

\section{Conflicts of Interest}

The authors declare that they have no conflicts of interest. 


\section{Acknowledgments}

This work is partially supported by Brazilian agencies: Conselho Nacional de Desenvolvimento Científico e Tecnológico (CNPq), Instituto Nacional de Engenharia de Superficies (INCT-INES), Coordenação de Aperfeiçoamento de Pessoal de Nível Superior (CAPES), and Fundacao de Amparo a Pesquisa no Estado do Rio de Janeiro (FAPERJ).

\section{References}

[1] F. Schedin, A. K. Geim, S. V. Morozov et al., "Detection of individual gas molecules adsorbed on graphene," Nature Materials, vol. 6, no. 9, pp. 652-655, 2007.

[2] S. S. Varghese, S. Lonkar, K. K. Singh, S. Swaminathan, and A. Abdala, "Recent advances in graphene based gas sensors," Sensors and Actuators B: Chemical, vol. 218, pp. 160-183, 2015.

[3] T. Wang, D. Huang, Z. Yang et al., "A review on graphenebased gas/vapor sensors with unique properties and potential applications," Nano-Micro Letters, vol. 8, no. 2, pp. 95-119, 2016.

[4] X. Li, W. Cai, J. An et al., "Large-area synthesis of high-quality and uniform graphene films on copper foils," Science, vol. 324, no. 5932, pp. 1312-1314, 2009.

[5] X. Xu, Z. Zhang, J. Dong et al., "Ultrafast epitaxial growth of metre-sized single-crystal graphene on industrial cu foil," Science Bulletin, vol. 62, no. 15, pp. 1074-1080, 2017.

[6] U. Hoefer, H. Böttner, A. Felske, G. Kühner, K. Steiner, and G. Sulz, "Thin-film $\mathrm{SnO}_{2}$ sensor arrays controlled by variation of contact potential-a suitable tool for chemometric gas mixture analysis in the TLV range," Sensors and Actuators B: Chemical, vol. 44, no. 1-3, pp. 429-433, 1997.

[7] A. Dey, "Semiconductor metal oxide gas sensors: a review," Materials Science and Engineering: B, vol. 229, pp. 206-217, 2018.

[8] K. Toda, R. Furue, and S. Hayami, "Recent progress in applications of graphene oxide for gas sensing: a review," Analytica Chimica Acta, vol. 878, pp. 43-53, 2015.

[9] A. Salehi-Khojin, D. Estrada, K. Y. Lin et al., "Polycrystalline graphene ribbons as chemiresistors," Advanced Materials, vol. 24 , no. 1, pp. 53-57, 2012.

[10] O. Leenaerts, B. Partoens, and F. M. Peeters, "Adsorption of $\mathrm{H}_{2} \mathrm{O}, \mathrm{NH}_{3}, \mathrm{CO}, \mathrm{NO}_{2}$, and no on graphene: a first-principles study," Physical Review B, vol. 77, no. 12, article 125416, 2008.

[11] G. Lee, G. Yang, A. Cho, J. W. Han, and J. Kim, "Defect-engineered graphene chemical sensors with ultrahigh sensitivity," Physical Chemistry Chemical Physics, vol. 18, no. 21, pp. 14198-14204, 2016.

[12] F. Rigoni, R. Maiti, C. Baratto et al., "Transfer of CVD-grown graphene for room temperature gas sensors," Nanotechnology, vol. 28, no. 41, article 414001, 2017.

[13] A. C. Ferrari and D. M. Basko, "Raman spectroscopy as a versatile tool for studying the properties of graphene," Nature Nanotechnology, vol. 8, no. 4, pp. 235-246, 2013.

[14] A. Eckmann, A. Felten, A. Mishchenko et al., "Probing the nature of defects in graphene by Raman spectroscopy," Nano Letters, vol. 12, no. 8, pp. 3925-3930, 2012. 


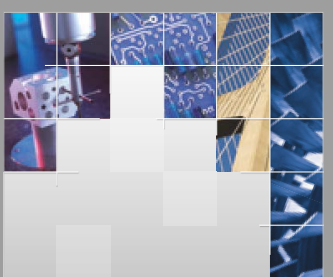

\section{Enfincering}
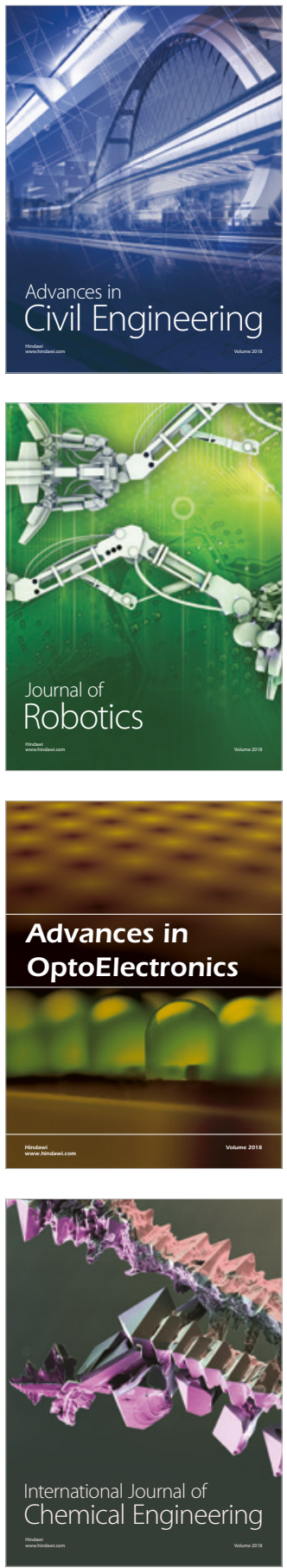

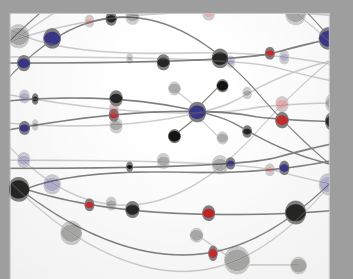

\section{Rotating \\ Machinery}

The Scientific World Journal

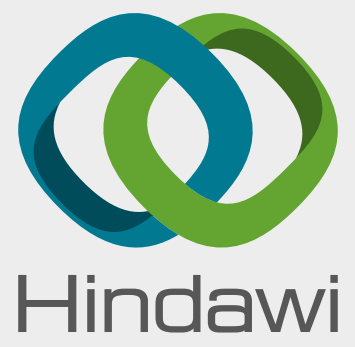

Submit your manuscripts at

www.hindawi.com
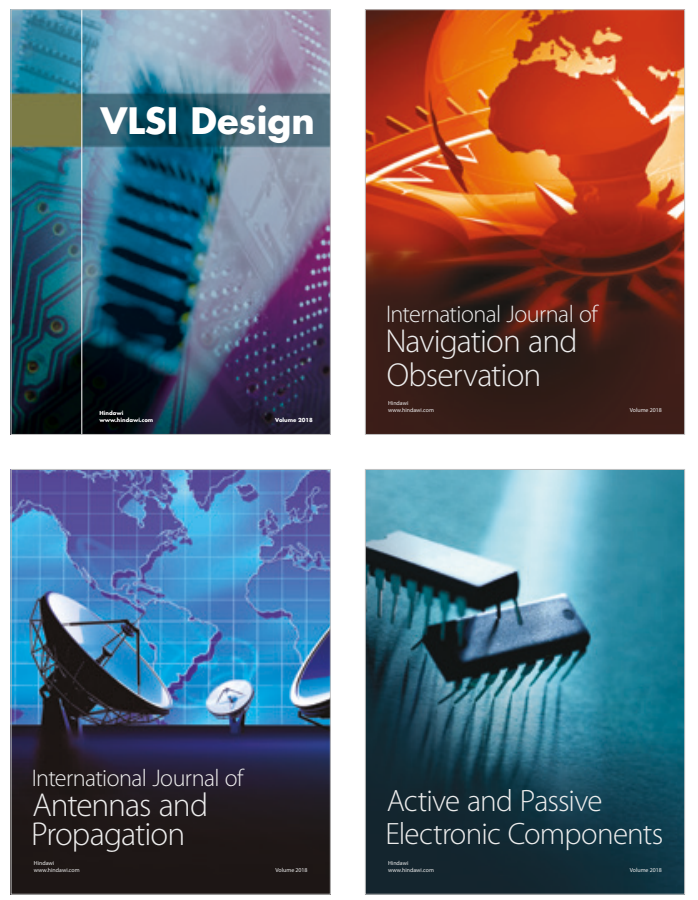
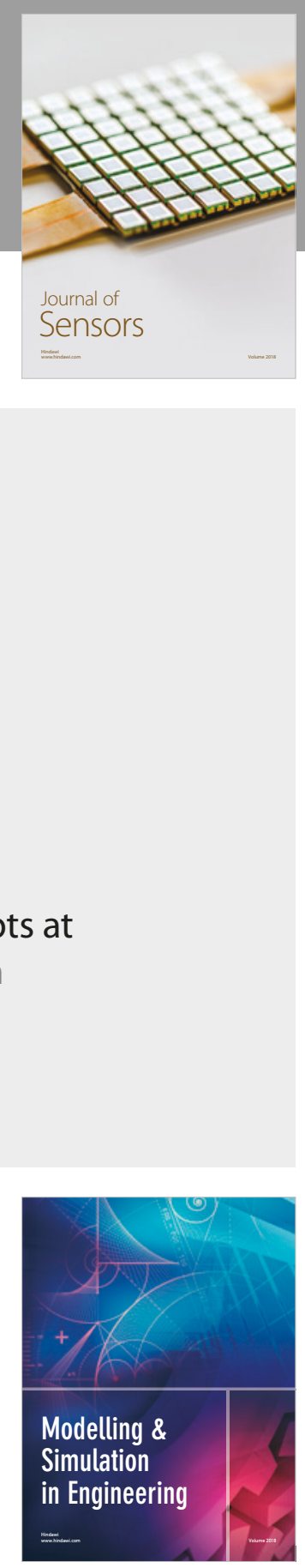

\section{Advances \\ Multimedia}
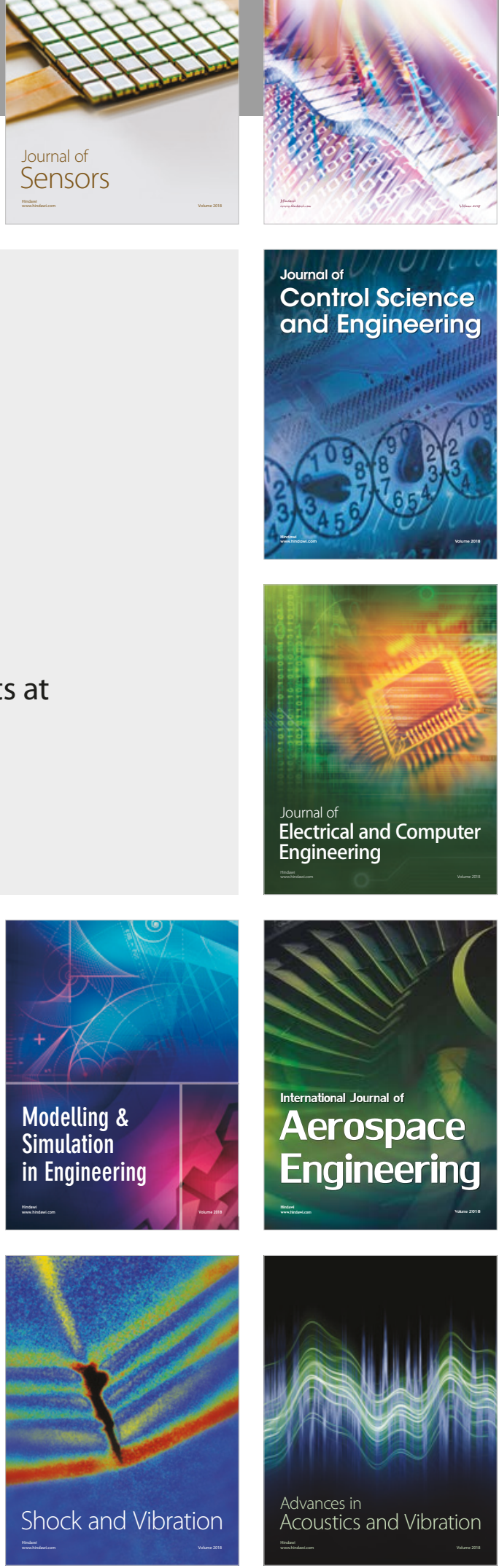